\title{
The Education Strategy Research on The Inheriting Traditional Sports Culture of Ethnic Minorities
}

\author{
Junlong Tian, Hui Li \\ Nanchang Institute of Science \&Technology, Nanchang Jiangxi 330108, China
}

Keywords: Traditional sports of ethnic minorities; inheritance; education strategy

\begin{abstract}
Education is the main way to realize the inheritance of traditional sports culture of ethnic minorities. From two aspects of school physical education system and folk sports education system to discuss the education strategy of national traditional sports culture inheritance, this paper is in order to realize the value of traditional sports culture.
\end{abstract}

\section{Introduction}

There are many ethnic minorities in our country, and the national sports culture is gorgeous and colorfl, the traditional sports items have been dug up to thousands of items. Their existence reflects the diversity of culture, enrich people's daily life, and has great value of inheritance. Among them, education is the main means of inheriting and developing these huge and valuable intangible cultural heritage. This article is based on the two perspectives of school education and folk education to discuss the inheritance of traditional sports culture of ethnic minorities.

\section{The relationship between education and the inheritance of Ethnic Traditional Sports Culture}

Education is the main way to realize the inheritance of traditional sports culture of ethnic minorities. From the point of view of the essence of education, education has the ability to realize the inheritance of national sports culture. The main body of national cultural heritage is human, the culture of any nation is the objectification of human nature, and it can also provide better service for people. It can be said that people are the starting point and end result of sports culture. Education is the transmission of social health living experience and cultivating people's social activities. That is to say, the transfer of social culture (social life experience) is the basic function of education, this function is realized through the cultivation of human activities, so the education can cultivate minority sports culture consciousness and quality of the talents to realize the cultural heritage of ethnic minority traditional sports, this is the function and mission of the school education and the folk education.

The inheritance of the traditional sports culture of ethnic minorities shapes a new generation. The national traditional sports culture can promote the all round development of the people, it has the educational value of shaping the new people, and it is the indispensable content of education to cultivate the new people. The national traditional sports culture can increase people's knowledge and improve people's ideas, and affect the development of human intelligence and non-intelligence factors. For example: learning chess is beneficial for the overall observation, sports dance obvious promoting effect on the rhythm of intelligence, equestrian are kinesthetic intelligence; during the game and confrontational sports, mobilize and inspire the winning motivations to 
participate in games and sports; in the activities of the successful experience is necessary adolescent emotional enhancement, frustration and failure can also exercise perseverance and strong will. Therefore, choose the national traditional sports items introduced in local colleges and schools, not only can solve the shortage of funding for education in ethnic minority areas,but also can solve the shortage of sports equipment, and it can make the development have qualified successors of traditional minority sports, promote the popularization and improvement of traditional sports activities.

To sum up, the inheritance and education of ethnic minority traditional sports culture has an inherent connection. So, how do we use the principle of education service to the heritage and development of minority traditional sports culture, we need to establish and improve the system of school physical education and give full play to the role of education system of folk sports, make both together jointly realize the inheritance and development of traditional ethnic sports culture.

\section{Cultivate national traditional sports talent from school physical education system}

Development of school-based curriculum in primary and secondary schools,introduction of national traditional sports. Curriculum system is the core of the process of cultivating talents in a series of projects, it is to achieve the goal of personnel training, it is the primary guarantee of teaching content, and the basis for the implementation of evaluation. Reasonable curriculum system design is the blueprint for the construction of personnel training project, it is the key to achieve the goal of personnel training. Therefore, in order to achieve the goal of cultivating national traditional sports talents, it is necessary to emphasize the proportion of national traditional sports items in the curriculum system. The educational administrative institutions and the primary and middle schools in the ethnic areas should actively develop the local curriculum and school-based curriculum. There are a large number of national traditional sports items, they are not the system, only in line with certain conditions, after screening to enter the school curriculum can determine the value of its curriculum resources development. We should follow certain principles when we choose the course content.

The first sieve is the philosophy of education, sports requirements selected must be conducive to the realization of the ideal of education and education aim to cultivate all-round development of people, reflect the needs of social development and progress. The second sieve is learning theory, that is choice of sports in teaching to meet the characteristics of physical and mental development of students, meet the students' interests and development needs. The third sieve is teaching theory, namely sports were selected to help the teachers implement the teaching reality, and the level of teachers' education training to adapt. After the three sieve screening leaving the national traditional sports curriculum resources, with the prerequisite in reality in physical education. Note that the "sieve theory" after the screening of traditional ethnic sports is a lot, because most of China's traditional ethnic sports are entertainment, promote physical and mental health effects, it is suitable for primary and secondary school students' physical and mental development, simple and easy for teaching.

Because there are a large number of national traditional sports, each school must be based on the actual situation of the local people to choose. In the northeast region of the school to choose skating, skiing and other ice and snow project, the project is suitable for the selection of the Mongolia grassland prairie schools, swimming and other water projects for the southern waters of the school choice. While the number of projects that no restrictions on the geographical environment, such as Korean springboard and swing, a lot of people are popular wrestling and Yajia can promote nationwide. Of course, each school should be based on the choice of the nation's traditional 
projects.

Colleges and universities should strengthen the development of national traditional sports specialty and train specialized talents. China's Ministry of Education issued the undergraduate and graduate students in the professional national traditional sports, it is clear that the state attaches great importance to the development of national traditional sports. We must realize the inheritance and development of traditional ethnic sports culture, we must cultivate a number of intermediate and senior specialized talents in higher education system, to engage in national traditional sports culture research and the dissemination of the work, so that our national traditional sports culture can have good development under the guidance of the theory. Colleges and universities in the national sports colleges and universities should be based on their own actual situation, and gradually set up a national traditional sports professional, for the development of national traditional sports culture and training of senior professionals. In addition, the establishment of the national traditional sports professional, to promote the basic education in the field of traditional ethnic sports development, to choose to study traditional sports projects to attract more students to enter the University, by virtue of the threshold. At the same time, in the field of basic education, the national traditional sports courses are well established, and the corresponding teachers will be needed. In turn, it provides employment opportunities for the national traditional sports professionals. So, in the National Traditional Sports in the field will achieve docking of higher education and basic education, it has formed a complete system, promote each other, develop each other better, and finally realize the inheritance and development of traditional ethnic sports culture in the school system, and promote the whole society in the inheritance and development. It can be seen that colleges and universities in minority areas should strengthen the establishment of national traditional sports specialty.

However, due to various reasons, set up the national traditional sports professional faculties for colleges and universities of ethnic minority areas are still rare. In the future development in ethnic colleges should put the region focus on national sports into professional courses to learn actively, the establishment of the national traditional sports professional, for the national cultural heritage and make its due contribution. The major of sports colleges also should be combined with their own actual situation, in the stage of postgraduate education the establishment of the national traditional sports professional training of senior specialized talents for the development of national traditional sports culture, for undergraduate teaching and research work related services.

In the training program of national traditional sports talents, the goal of personnel training and the determination of curriculum system are important. According to the characteristics of the development of modern education and national traditional sports itself, can aim to "cultivate a national traditional sports sports skills and the comprehensive development of the cultivation of innovative talents of Chinese traditional sports specialty talents." According to the actual situation of the teachers, we can draw lessons from the experience of the sports colleges and universities which have been set up in china. At the same time, we should also pay attention to reflect the national characteristics, pay attention to the proportion of general education curriculum, elective courses and vocational courses.

\section{Constructing the system of folk physical education to improve the national tradition sports culture inheritance system}

Because some of the traditional project does not have the conditions to enter the school, and the school system is also not with the ability to accommodate all of the project, so this part should not enter the school projects need to rely on private education system to realize their inheritance. 
The construction of folk physical education system should be carried out from two aspects of family sports and social sports. Family sports and social sports is an important part of family education and social education, it is a beneficial supplement for school education, we only build the school physical education system to the inheritance of national traditional sports culture is not enough, achieve the combination of the three, in order to achieve the emphasis on education of the whole function, the formation of integration of education and society the pattern of real inheritance and development of national traditional sports culture. In addition, as mentioned above, some of the national traditional sports can not enter the school curriculum system, then we can only rely on folk education to complete its inheritance and development.

Family sports. Family sports is an important part of family education, which has the characteristics of family education. It is a kind of family education based on kinship. Family is a place where people are born, and the place where they live and grow. Family is the most important place, people gets the first time enter into social life. It is based on the important position and role of family in human life, we should attach great importance to the role of family sports in the study of national sports cultural heritage.

Family sports is to care about the child's physical and mental health, and promote the normal development of their physical and mental health. Family sports content is rich and varied, as long as there is conducive to the child into sports activities can be used, of course, national traditional sports with its simple and entertaining features is one of the main aspects, such as the most popular children's shuttlecock, jump house, playing gyro. Moreover, national sports itself comes from life, and rich life sentiment, parents can guide children for sports games are at work or leisure time, this will not only enhance the affection, and the development of the athletic ability of children. For example, there are fish aquarium wushu boxing, duck boxing, a pole stick instrument, there are a variety of chess, and the traditional festival of horse racing, the top pole, turning table and other activities, which are often involved in family life work, parents can according to their own good activities to guide the children to the nearest handy these play the national physical activities, to cultivate children's interest, cooperate with the school and society to complete the national cultural heritage.

Social sports. Social sports is an important part of social education, it also has the characteristics of social education, it can promote individual interests, hobbies, personality and special skills development, it is an indispensable part of the whole education system, it can promote the school education and family education. According to the characteristics of traditional sports itself, closely focusing on folk sports and traditional festivals, traditional festivals that contained in national physical culture education significance.

Traditional festival is a complex cultural structure, it is a comprehensive social phenomenon. It reflects the life, history, psychology, personality, morality, religion and culture. It can be said that the traditional festival is an important part of Chinese contend a brilliant folk culture, and traditional ethnic sports is a traditional festival of the climax, so the occurrence of traditional festivals of national sports can be a good representative of folk culture in folk sports. It can be said that the traditional festival is the stage for the survival and development of some excellent national traditional sports. For example, the aquarium of the "horse race", because the location of horses and other reasons, do not have the conditions in schools, and it is the climax of the end, no horse, also lost the boiling hot, lost its soul Festival, so that the horse racing is the outstanding sports culture aquarium, aquarium is also an important part of culture, it must not be lost. But because the school does not have the "horse race" into the school curriculum, then it can only rely on the way of social education heritage, held annually in the end on the slope in the race to continue this activity, if not 
the end of horse racing, horse racing is likely so the aquarium slowly disappeared. Visible, the traditional festival is the inheritance and development of national sports culture stage, the government should pay attention to this kind of education, pay attention to the protection of traditional festivals in the development of national sports. The government can organize some temporary educational institutions, during the festival, to intensify propaganda, and encourage more people to participate, so people will drive on weekdays for the movement in attention and participation, so as to realize the inheritance and development of traditional sports culture.

\section{Conclusion}

Inheritance of traditional sports culture of ethnic minorities is has great significant, we should through various forms to development of traditional minority sports, so education role should not be underestimated, by strengthening the traditional ethnic sports culture in education, it can promote the healthy development of national minority sports.

\section{References:}

[1] Xia Q. Education Strategy Research on the Inheritance of the Traditional Sports Culture of Minority Ethnic[J]. Journal of Sports \& Science, 2010.

[2] Huang S, Xiao-Yan G U, Zhang D X, et al. On the Cultural Value and Inheritance Strategy of the Traditional Sports of Shui Ethnic Group[J]. Journal of Qiannan Normal College for Nationalities, 2006, 56(4):548-57.

[3] Jin D G. Discussed Shui Ethnic Group's Intangible Cultural Heritage of the Development, Utilization and Protection[J]. Journal of Bijie University, 2012.

[4] He Y, Wen B, Shan KR. [The distribution of Y-chromosome haplotypes of Shui ethnic in Sandu,Guizhou].[J]. Hereditas, 2003, 25(3):249-252. 